\title{
Harvest and density-dependent predation drive long term population decline in a northern ungulate
}

\author{
Robby R. Marrotte ${ }^{1}$, Brent Patterson ${ }^{2}$, and Joe M. Northrup ${ }^{2}$ \\ ${ }^{1}$ Trent University \\ ${ }^{2}$ Ontario Ministry of Natural Resources and Forestry
}

May 27, 2021

\begin{abstract}
The relative effect of top-down versus bottom-up forces in regulating and limiting wildlife populations is an important theme in ecology. Untangling these effects is critical for basic understanding of trophic dynamics and effective management. We examined the drivers of moose abundance by integrating two sets of observations to create one of the largest existing spatiotemporal datasets on ungulate population dynamics globally. We documented a $20 \%$ population decline. At high density, moose were regulated by intraspecific competition. Predation primarily limited population growth, except at low density, where it was regulating. Harvest was largely additive and contributed to population decline. Our results provide strong evidence for density dependent predation, highlighting that population dynamics are context dependent and vary strongly across gradients in climate, forest type and predator abundance. These results clarify longstanding questions in population ecology and highlight the complex relationships between natural and human-caused mortality in driving ungulate population dynamics.
\end{abstract}

\section{Hosted file}

moose_ecol_letters_v3.docx available at https://authorea.com/users/367138/articles/523774harvest-and-density-dependent-predation-drive-long-term-population-decline-in-anorthern-ungulate 